\title{
Minimally Invasive Lumbar Pedicle Screw Fixation Using Cortical Bone Trajectory - A Prospective Cohort Study on Postoperative Pain Outcomes
}

\author{
Yi-Ren Chen ${ }^{1}$, Sayantan Deb ${ }^{2}$, Lan Pham ${ }^{1}$, Harminder Singh ${ }^{1}$ \\ 1. Department of Neurosurgery, Stanford University Medical Center 2. Medical School, Stanford \\ University School of Medicine
}

$\square$ Corresponding author: Yi-Ren Chen, yirenchen@stanford.edu

Disclosures can be found in Additional Information at the end of the article

\section{Abstract}

Objective: Our study aims to evaluate the clinical outcomes of cortical screws in regards to postoperative pain.

Background: Pedicle screw fixation is the current mainstay technique for posterior spinal fusion. Over the past decade, a new technique called cortical screw fixation has been developed, which allows for medialized screw placement through stronger cortical bone. There have been several studies that showed either biomechanical equivalence or superiority of cortical screws. However, there is currently only a single study in the literature looking at clinical outcomes of cortical screw fixation in patients who have had no prior spine surgery.

Methods: We prospectively looked at the senior author's patients who underwent cortical versus pedicle lumbar screw fixation surgeries between 2013 and 2015 for lumbar degenerative disease. Eighteen patients underwent cortical screw fixation, and 15 patients underwent traditional pedicle screw fixation. We looked at immediate postoperative pain, changes in short-term pain (six to 12 weeks post-surgery), and changes in long-term pain (six to eight months). All pain outcomes were measured using a visual analog scale ranging from 1 to 10 . Mann-Whitney or Kruskal-Wallis tests were used to measure continuous data, and the Fisher Exact test was used to measure categorical data as appropriate.

Results: Our results showed that the cortical screw cohort showed a trend towards having less peak postoperative pain $(\mathrm{p}=0.09)$. The average postoperative pain was similar between the two cohorts $(p=0.93)$. There was also no difference in pain six to 12 weeks after surgery $(p=0.8)$. However, at six to eight months, the cortical screw cohort had worse pain compared to the pedicle screw cohort $(\mathrm{p}=0.02)$.

Received 05/23/2016

Review began 06/04/2016 Review ended 07/15/2016 Published 07/26/2016

C) Copyright 2016

Chen et al. This is an open access article distributed under the terms of the Creative Commons Attribution License CC-BY 3.0., which permits unrestricted use, distribution, and reproduction in any medium, provided the original author and source are credited.
Conclusions: The cortical screw patients showed a trend towards less peak pain in the shortterm (one to three days post-surgery) and more pain in the long-term (six to eight months post-surgery) compared to pedicle screw patients. Both cohorts had a statistically significant reduction in pain levels compared to preoperative pain. More studies are needed to further evaluate postoperative pain, long-term functional outcomes, and fusion rates in patients who undergo cortical screw fixation.

Categories: Pain Management, Neurosurgery, Orthopedics 


\section{Cureus}

Keywords: cortical screws, outcomes, prospective cohort study, postoperative pain

\section{Introduction}

Every year, over 120,000 lumbar fusions are performed nationwide for degenerative and traumatic spine conditions [1]. The fusions are mostly done with pedicle screw fixation, the current standard technique for accomplishing posterior spinal fusion, due to its reliable fusion rates and construct stability. However, the technique is invasive and requires significant lateral spinal dissection in order to properly place the screws, resulting in large incisions and long operative times. In keeping with the push to perform more minimally invasive spine surgery, a new technique of spinal instrumentation has been developed whereby screws are placed through a starting point at the junction of the superior articular process and pars. This technique is called cortical screw fixation (Figure 1).
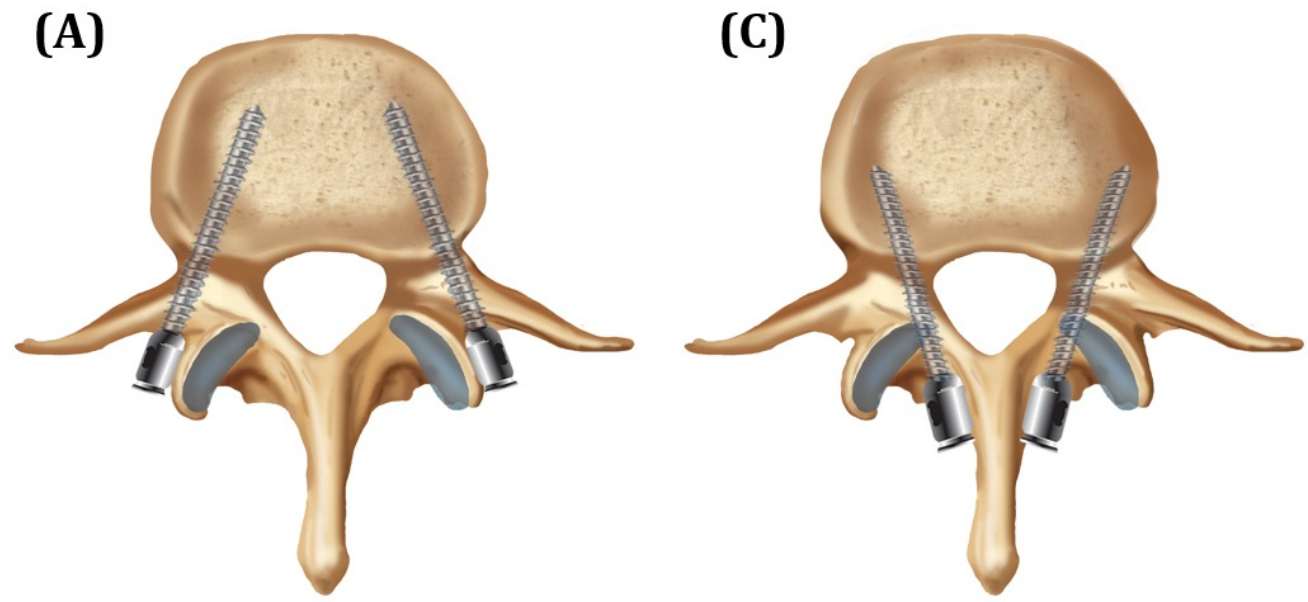

(B)

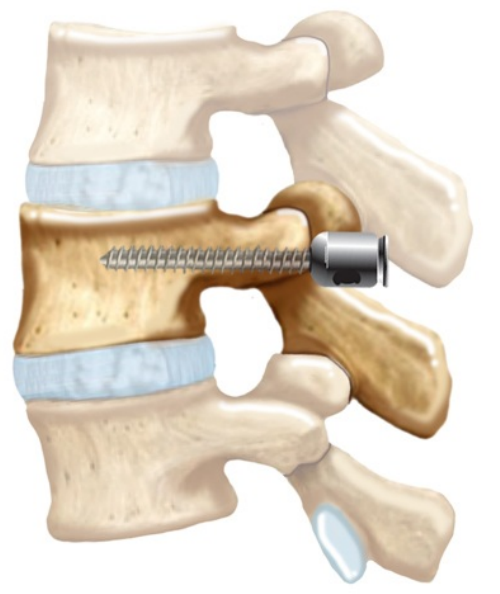

(D)

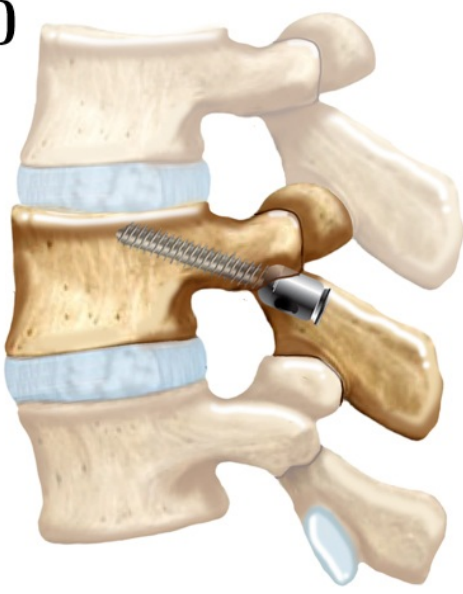

FIGURE 1: Cortical Versus Pedicle Screw Fixation Trajectories

(A and B) Traditional pedicle screw trajectories in (A) axial and (B) sagittal views. (C and D) Cortical screw trajectories in (C) axial and (D) sagittal views.

Over the past decade, there have been several studies that showed either biomechanical equivalence or superiority of cortical screws compared to pedicle screws [2-11]. One study by Baluch, et al. looked at 17 vertebral levels that underwent quantitative computed tomography (CT) [2]. On one side, cortical screws were placed, and on the other, traditional pedicle screws 


\section{Cureus}

were placed. Cortical screws demonstrated significantly improved resistance to toggle testing, requiring 184 cycles to reach $2 \mathrm{~mm}$ of displacement compared to 102 cycles for the traditional pedicle screws $(\mathrm{p}=0.002)$.

Due to the promising biochemical studies and the minimally invasive nature of cortical screws, some surgeons are starting to utilize the technique in lumbar fusions. However, there is currently only one study in the literature looking at the clinical efficacy or outcomes of cortical screws in non-redo patients [12]. In that prospective randomized non-inferiority trial, Lee, et al. showed that cortical screw fixation in posterior lumbar interbody fusion (PLIF) provides similar clinical and radiological outcomes compared to pedicle screw fixation. Most past studies have reported on biomechanical strength and not on clinical outcomes [2-10]. In this study, we focus on postoperative and long-term pain in patients who underwent cortical versus pedicle screw fixation in the lumbar spine. Our goal was to evaluate the hypothesis that cortical screw patients should have less postoperative pain due to the smaller incision, less dissection needed to find entry points, and more intraoperative preservation of muscle attachments (Figure 2). Low back pain is often related to muscular stabilization of the "neutral zone" in the back, and the lumbar multifidus muscles are important stabilizers of this neutral zone. Studies have shown that dysfunction of these muscles, such as after surgery, is associated with increased pain [13].
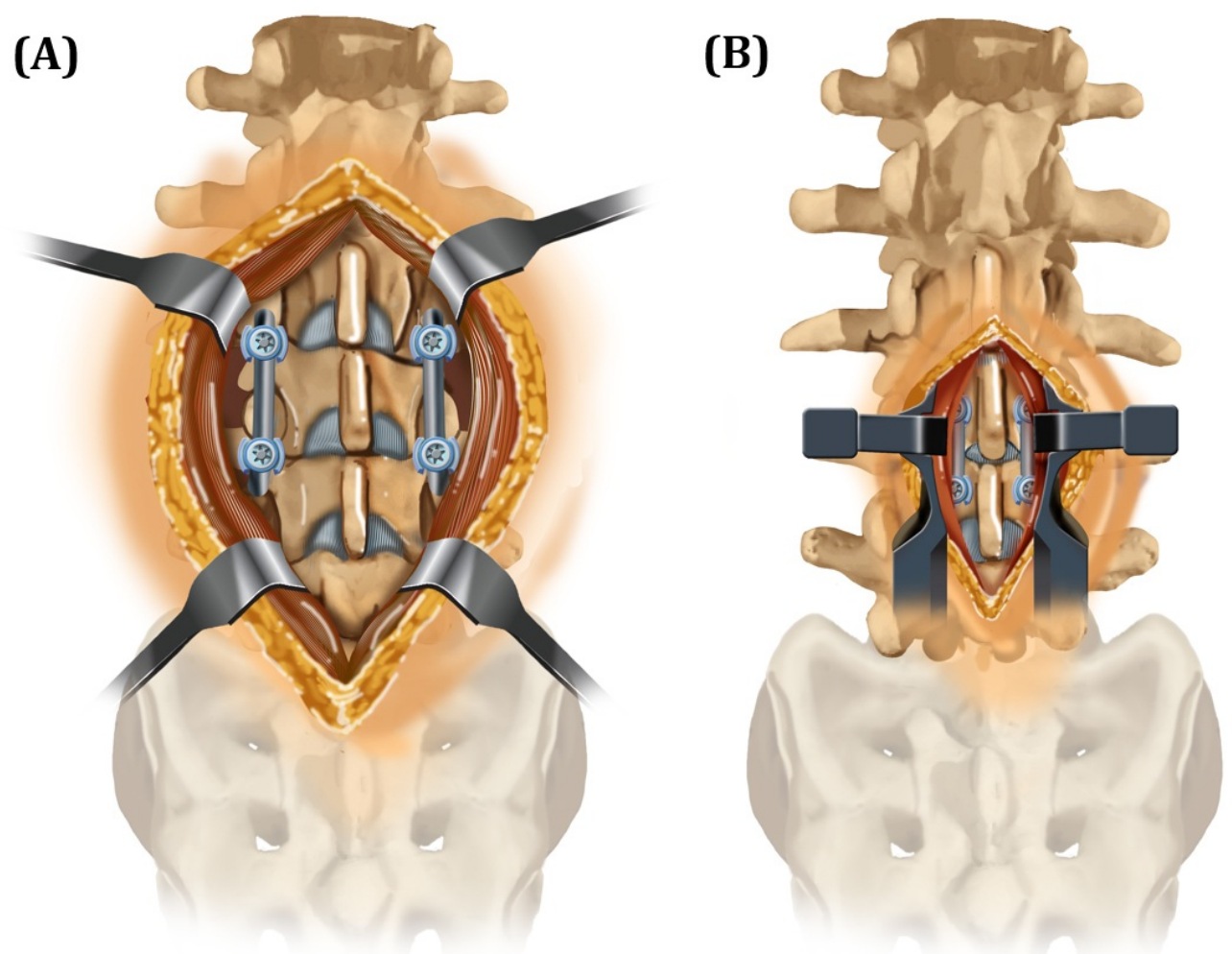

\section{FIGURE 2: Soft Tissue Exposure Required for One-Level Lumbar Fixation}

(A) Traditional pedicle fixation. (B) Cortical screw fixation.

\section{Materials And Methods}




\section{Cohort selection}

We prospectively enrolled patients with lumbar degenerative disease and instability who needed lumbar fusion from 2013 to 2015 at the Santa Clara Valley Medical Center (SCVMC) in San Jose, CA. SCVMC is a level one trauma center and the county hospital wing of Stanford University Medical Center. IRB approval for the prospective data registry was obtained through SCVMC (approval \#15-026ER). Informed patient consent was obtained at the time of treatment. All patients underwent pedicle or cortical screw placement by the senior author. Patients who underwent surgery because of trauma or infection, such as osteomyelitis, were excluded. In total, 18 patients underwent cortical screw fixation, and 15 underwent pedicle screw fixation. Most of the patients in the lumbar pedicle screw fixation group had their spinal fixation surgeries before the institution of lumbar cortical trajectory screws at SCVMC. The only patients who had pedicle screw fixation done after the institution of cortical trajectory screws were the ones with small pedicles ( $<7 \mathrm{~mm}$ diameter) on preoperative CT scans.

All patients received the same pain regimen postoperatively, with a morphine patientcontrolled analgesia pump for 24 hours, followed by long-acting OxyContin and IV morphine and/or Percocet thereafter during the hospital stay. Patients were discharged home on oral Percocet.

\section{Surgical technique}

Traditional pedicle screws were placed using the technique described by Weinstein, et al. [14]. A standard skin incision was made and lateral muscle dissection was performed to expose the transverse processes. An awl was used to breach the cortex at the lateral facet surface, and a pedicle finder was used to extend the trajectory. A tap was then used and screws placed. Overall, a total of 23 levels were fused in the pedicle group. In addition, arthrodesis was also performed in the lateral gutters over the transverse processes. No interbody grafts were used.

The cortical screw starting point is at the lateral aspect of the pars interarticularis and, therefore, requires significantly less lateral muscle dissection. The angulation is medial to lateral, rather than lateral to medial as in the traditional pedicle screw technique. Screws are inserted approximately 10 degrees laterally in the axial plane and 25 degrees cranially in the sagittal plane, although actual angulations are determined by intraoperative fluoroscopy (Figure 1) [4]. Pedicles, $7 \mathrm{~mm}$ in diameter, were used as the minimum cut-off in order to safely perform cortical screw fixation without lateral vertebral body breach. A total of 26 levels were fused in the cortical group. In addition, arthrodesis was also performed over the facet joints with a high-speed drill.

\section{Outcome measurements}

We looked at peak pain and average immediate postoperative pain from 24 to 72 hours after surgery. We also looked at changes in short-term pain (six to 12 weeks post-surgery) and changes in long-term pain (six to eight months), when compared to preoperative pain in the two cohorts. All pain outcomes were measured using a visual analog scale ranging from 1 to 10 .

\section{Statistical analysis}

Mann-Whitney or Kruskal-Wallis tests were used to analyze the difference in pain outcomes between the two groups and over time, respectively. Categorical data was analyzed using Fisher's exact test. A p - value of less than 0.05 was considered statistically significant. GraphPad Prism v 6.0 was used to conduct all statistical analyses.

\section{Results}




\section{Cureus}

A total of 36 patients were included in the study. Three were excluded because of trauma and infection being the indications for fusion, with a total of 33 patients remaining. Eighteen patients underwent cortical screw fixation and 15 underwent pedicle screw fixation. Overall, the patient characteristics in the cortical versus the pedicle screw groups were similar (Table 1).

\begin{tabular}{|c|c|c|c|}
\hline & Cortical Screw (n = 18) & Pedicle Screw ( $n=15)$ & P-value \\
\hline Age (mean \pm SE) & $53.39 \pm 1.97$ & $59.2 \pm 3.12$ & 0.12 \\
\hline Female (\%) & 38.9 & 86.7 & $0.01^{\star \star}$ \\
\hline Ever Smoked (\%) & 50 & 46.7 & 1.00 \\
\hline Preoperative Pain (mean \pm SE) & $7.61 \pm 0.36$ & $7.43 \pm 0.44$ & 0.79 \\
\hline
\end{tabular}

\section{TABLE 1: Patient Characteristics}

** indicates statistically significant

Age, preoperative pain, smoking status, and comorbidities were all similar, with the exception of gender; the pedicle screw group had more females (86.7\%) compared to the cortical screw group (38.9\%) $(\mathrm{p}=0.01)$. Degenerative disc (DD) disease was the predominant finding on MRI in both cohorts, and presenting pain symptoms were also similar (Table 2).

\section{Pathology}

\section{Cortical Screw Series}

Central and NFS: L5-S1 spondylosis with b/l pars defect

DD and NFS at L4-5 and L5-S1

Central stenosis L4-5, b/I NFS L5-S1

Severe central stenosis with Grade 1 anterolisthesis, b/l NFS

Central stenosis, left NFS - facet hypertrophy + synovial cyst

DD and NFS at L4-5 and L5-S1

Central stenosis and left NFS L5-S1

DD and right NFS

DD and left NFS

DD and left NFS - L3-4 and L4-5

DD and left NFS

\section{Presenting Pain Symptoms}

Levels

Fused

Back pain and bilateral radicular leg pain

L5-S1

Back pain and bilateral radicular leg pain

L4-S1

Back pain and left radicular leg pain

L4-S1

Back pain and bilateral radicular leg pain

L4-L5

Back pain and left radicular leg pain

Back pain and bilateral radicular leg pain

L4-S1

Back pain and neurogenic claudication

Back pain and bilateral radicular leg pain

L4-S1

Back pain and left radicular leg pain

Back pain and left radicular leg pain

Back pain and left radicular leg pain 


\section{Cureus}

Central stenosis, left NFS

DD and central stenosis, L4-5 and L5-S1

Central stenosis, NFS at L3-4 and L4-5 + synovial cyst

DD and right NFS

DD and left NFS

Central stenosis, left NFS

L5-S1 spondylosis with b/I NFS

\section{Pedicle Screw Series}

DD and central and right NFS L5-S1

Central stenosis and b/l NFS

Central stenosis and left NFS

Central stenosis and b/I NFS L3-5

L4-S1 central stenosis and right NFS

DD and central stenosis

\section{L3-5 central stenosis and b/I NFS}

Central stenosis and b/I NFS, anterolisthesis L4 on L5

Central stenosis and right NFS

Central stenosis and b/l NFS

DD and central stenosis

L5 on S1 anterolisthesis and b/I NFS

Central stenosis with b/l NFS

Stage II anterolisthesis L3 on L4

Central stenosis and anterolisthesis L4 on L5
Back pain and left radicular leg pain

L4-L5

Back pain and right radicular leg pain

L4-S1

Back pain and right radicular leg pain

Back pain and right radicular leg pain

L4-S1

Back pain and bilateral radicular leg pain

L4-5

Back pain and left radicular leg pain

Back pain and right radicular leg pain

Back pain and bilateral radicular leg pain

L5-S1

Back pain and bilateral radicular leg pain

L3-L4

Back pain and left radicular leg pain

Back pain and bilateral radicular leg pain

L3-S1

Low back pain and right radicular leg pain

Low back pain and neurogenic claudication

Back pain and bilateral radicular leg pain

L3-L5

Back pain and left radicular leg pain

L4-L5

Low back pain and right radicular leg pain

Back pain and bilateral radicular leg pain

L4-5

Back pain and bilateral radicular leg pain

L4-S1

Back pain and bilateral radicular leg pain

L5-S1

Back pain and Left radicular leg pain

Back pain and neurogenic claudication

Back pain and bilateral radicular leg pain

\section{TABLE 2: Patient Pathology, Presenting Symptoms, and Levels Fused}

DD - degenerative disease; NFS - neuroforaminal stenosis; b/l - bilateral 


\section{Cureus}

in Figure 3. However, there was a trend towards cortical screw patients having less peak postoperative pain, at a pain score of 7.94 versus $9(\mathrm{p}=0.09)$.

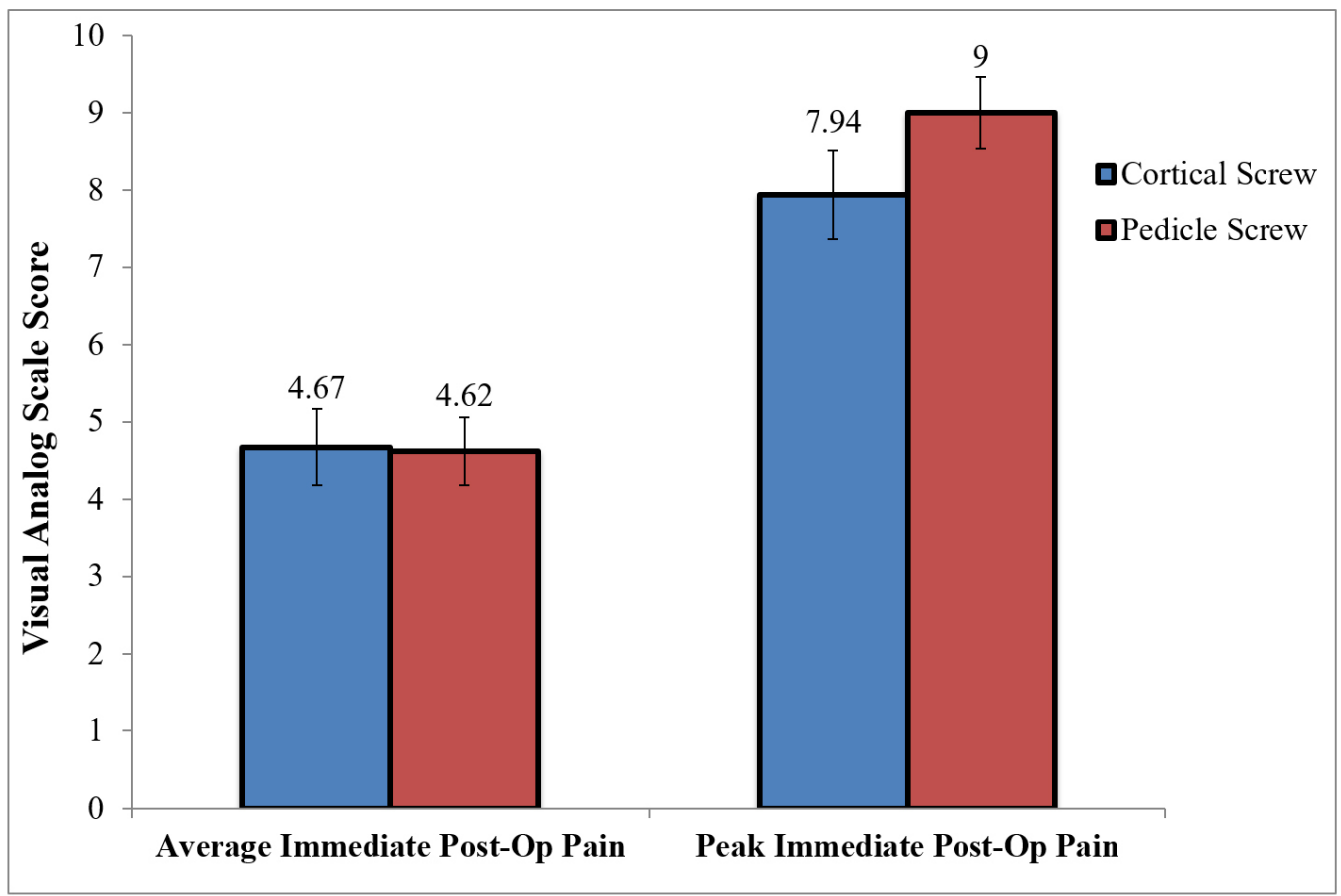

FIGURE 3: Immediate Postoperative Pain in Cortical Versus Pedicle Screw Patients

There was no difference in postoperative pain at the time of short-term follow-up at six to 12 weeks, with an average pain score of 4.97 in the cortical group compared to 4.93 in the pedicle group $(\mathrm{p}=0.8)$ (Figure 3).

However, the cortical screw patients did have more pain at the six to eight-month follow-up, with a pain score of 6.14 compared to 3.8 in the pedicle group $(p=0.02)$ (Figure 4 ).

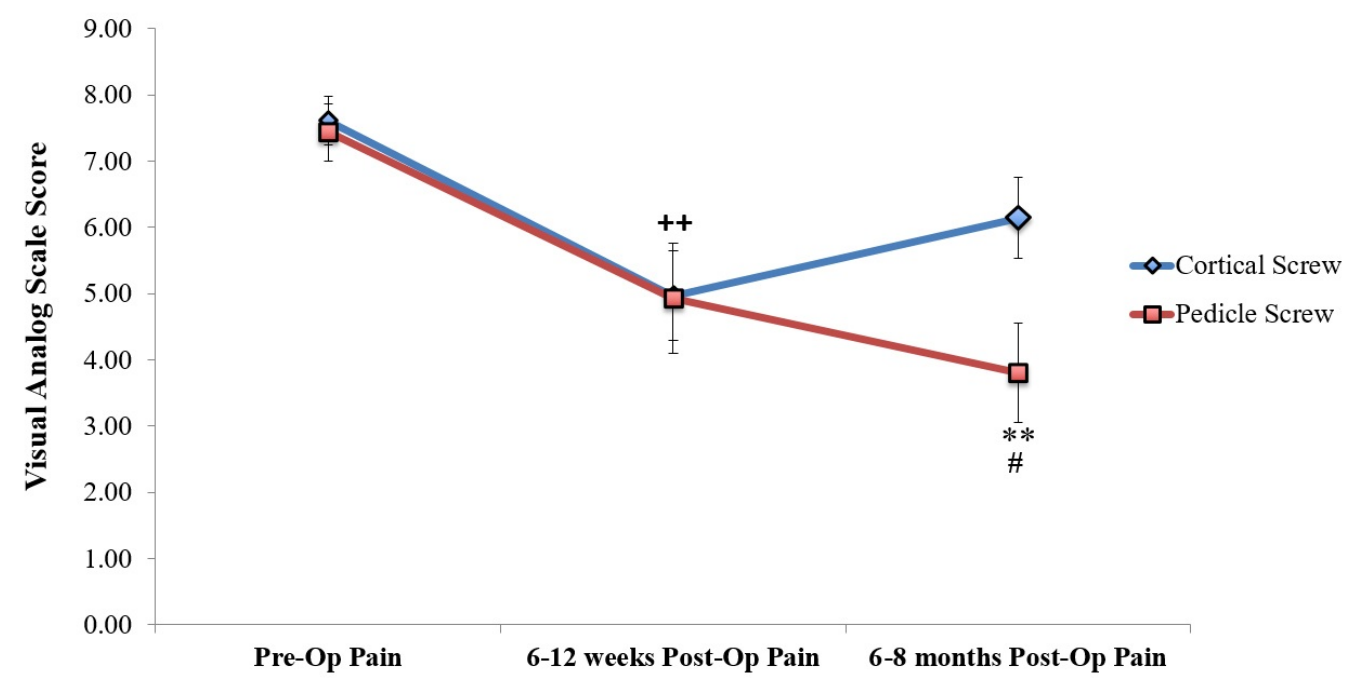




\section{Cureus}

FIGURE 4: Long-Term Postoperative Pain in Cortical Versus

\section{Pedicle Screw Patients}

Both groups had a statistically significant reduction in pain levels compared to preoperative pain, as seen in Table 3.

\begin{tabular}{|c|c|c|c|c|c|}
\hline & Preop & $\begin{array}{l}\text { 6-12 } \\
\text { weeks }\end{array}$ & $\begin{array}{l}\text { 6-8 } \\
\text { months }\end{array}$ & $\begin{array}{l}\text { p-value (Kruskal-Wallis) over time } \\
\text { within group }\end{array}$ & $\begin{array}{l}\text { Multiple } \\
\text { comparisons }\end{array}$ \\
\hline $\begin{array}{l}\text { Mean Pain Cortical Screw } \\
\text { (mean } \pm \text { SE) }\end{array}$ & $\begin{array}{l}7.61 \pm \\
0.36\end{array}$ & $\begin{array}{l}4.97 \pm \\
0.68\end{array}$ & $\begin{array}{l}6.14 \pm \\
0.61\end{array}$ & 0.004 & $\begin{array}{l}\text { Pre-op vs. 6-12 } \\
\text { weeks }^{\star \star}\end{array}$ \\
\hline $\begin{array}{l}\text { Mean Pain Pedicle Screw } \\
\text { (mean } \pm \text { SE) }\end{array}$ & $\begin{array}{l}7.43 \pm \\
0.44\end{array}$ & $\begin{array}{l}4.93 \pm \\
0.84\end{array}$ & $\begin{array}{l}3.80 \pm \\
0.75\end{array}$ & 0.002 & $\begin{array}{l}\text { Pre-op vs. 6-8 } \\
\text { months** }\end{array}$ \\
\hline p-value Between Groups & 0.79 & 0.80 & $0.02^{\star \star}$ & & \\
\hline
\end{tabular}

TABLE 3: Numerical Data and Statistical Analysis of Long-term Postoperative Pain in Cortical Versus Pedicle Screw Patients

${ }^{* *}$ indicates levels of significance

The raw data for all patients in the study are shown in Tables 4-5. 


\section{Cureus}

\begin{tabular}{|c|c|c|c|c|c|c|}
\hline Age & $\begin{array}{l}\text { Immediate Average } \\
\text { Postop Pain }\end{array}$ & $\begin{array}{l}\text { Immediate Peak } \\
\text { Postop Pain }\end{array}$ & $\begin{array}{l}\text { 6-12 Weeks } \\
\text { Postop Pain }\end{array}$ & $\begin{array}{l}\text { 6-8 Months } \\
\text { Postop Pain }\end{array}$ & $\begin{array}{l}\text { Ever } \\
\text { Smoked }\end{array}$ & $\begin{array}{l}\text { Significant } \\
\text { Comorbidities }\end{array}$ \\
\hline 50 & 5.733 & 10 & 7 & 7 & yes & Neuropathy \\
\hline 44 & 6.313 & 9 & 6 & 5 & yes & COPD \\
\hline 42 & 3.222 & 7 & 4 & NA & no & $\begin{array}{l}\text { Chronic neck } \\
\text { pain }\end{array}$ \\
\hline 59 & 5.5 & 10 & 0 & 5 & yes & DM, HTN, HLD \\
\hline 59 & 4.958 & 10 & 0 & 6 & yes & DM, OA, Sciatica \\
\hline 67 & 5.375 & 10 & 0 & 6 & no & HTN, HLD \\
\hline 52 & 2.875 & 6 & 7 & 8 & yes & HTN, HLD, DM \\
\hline 57 & 8.286 & 10 & 7 & 10 & no & HTN \\
\hline 35 & 8.5 & 9 & 9 & 8 & yes & Seizures \\
\hline 50 & 6.154 & 9 & 7 & 7 & no & DM, HTN, CKD \\
\hline 56 & 4.25 & 8 & 6 & 7 & no & Lumbago \\
\hline 64 & 2.4 & 9 & 4 & 5 & no & DM, HTN \\
\hline 58 & 3.429 & 6 & 6 & 7 & yes & HTN \\
\hline 44 & 4 & 7 & 5 & 0 & yes & HTN \\
\hline 49 & 4.077 & 7 & 4 & 5 & yes & DM, HTN \\
\hline 55 & 3.133 & 7 & 4 & NA & no & GERD \\
\hline 59 & 0 & 0 & 8.5 & NA & no & DM, Migraine \\
\hline 61 & 6 & 9 & NA & NA & no & Fibromyalgia \\
\hline
\end{tabular}

\section{TABLE 4: Cortical Screw Patient Series}

COPD - chronic obstructive pulmonary disease; DM - diabetes mellitus; HTN - hypertension; HLD - hyperlipidemia; OA osteoarthritis; CKD - chronic kidney disease; GERD - gastroesophageal reflux disease; NA - Data not available 


\section{Cureus}

\begin{tabular}{|c|c|c|c|c|c|c|}
\hline Age & $\begin{array}{l}\text { Immediate Average } \\
\text { Post-Op Pain }\end{array}$ & $\begin{array}{l}\text { Immediate Peak } \\
\text { Post-Op Pain }\end{array}$ & $\begin{array}{l}\text { 6-12 Weeks } \\
\text { Post-Op Pain }\end{array}$ & $\begin{array}{l}\text { 6-8 Months } \\
\text { Post-Op Pain }\end{array}$ & $\begin{array}{l}\text { Ever } \\
\text { Smoker }\end{array}$ & $\begin{array}{l}\text { Significant } \\
\text { Comorbidities }\end{array}$ \\
\hline 47 & 7.167 & 9 & 9 & 7 & yes & $\begin{array}{l}\text { HTN, Neuropathy, } \\
\text { Lumbago, Seizures }\end{array}$ \\
\hline 77 & 5.6 & 10 & 7 & 5 & no & $\mathrm{CHF}$ \\
\hline 56 & 4.615 & 10 & 4 & 6 & yes & HTN, HLD, OA \\
\hline 49 & 6.286 & 10 & 9 & 5 & yes & $\begin{array}{l}\text { HTN, Seizures, } \\
\text { Sciatica }\end{array}$ \\
\hline 57 & 5.4 & 10 & 4 & 0 & no & Epilepsy, Sciatica, OA \\
\hline 71 & 4.364 & 10 & 7 & 9 & no & OA, DM, HTN, CKD \\
\hline 78 & 5.222 & 10 & 6 & 3 & no & DM, HTN, HLD \\
\hline 63 & 1.7 & 4 & NA & 2 & no & HTN, HLD, OA \\
\hline 63 & 4.1538 & 8 & 0 & 0 & yes & CAD \\
\hline 65 & 4.9444 & 9 & 5 & 4 & yes & HLD, HTN, DM \\
\hline 38 & 4.0714 & 9 & 5 & 0 & no & Lumbar stenosis \\
\hline 62 & 5.375 & 10 & 0 & 0 & yes & DM, HTN, HLD CHF \\
\hline 39 & 5 & 10 & 8 & 7 & no & DM \\
\hline 65 & 0.81 & 7 & 0 & 4 & no & RA \\
\hline 58 & NA & NA & 5 & 5 & yes & HTN, OA \\
\hline
\end{tabular}

\section{TABLE 5: Pedicle Screw Patient Series}

CHF - congestive heart failure; DM - diabetes mellitus; HTN - hypertension; HLD - hyperlipidemia; OA - osteoarthritis; CKD chronic kidney disease; CAD - coronary artery disease; RA - rheumatoid arthritis; NA - Data not available

\section{Discussion}

Multiple biomechanical studies have shown equivalence or superiority of the cortical bone trajectory compared to the standard technique for pedicle screw fixation [2-3, 5-10]. Most studies show that cortical screws traverse denser cortical bone and, thus, result in increased pullout strength and improved rigidity. This has theoretical advantages for patients with osteoporosis, failed fusion requiring reoperation, and even first-time fusions for degenerative disease and spinal instability. However, there is only one study looking at the efficacy and clinical outcomes of cortical screw fixation in previously non-instrumented patients. In their prospective randomized trial, Lee, et al. showed that cortical screw fixation with interbody fusion provides comparable pain reduction and fusion rates to that of pedicle screw fixation with interbody fusion. 
Another study in the literature that is non-cadaveric is by Rodriguez, et al. [15]. The authors retrospectively reviewed five patients who underwent cortical screw fixation and posterior interbody grafting for adjacent segment lumbar disease. All cases were reoperations after prior lumbar instrumentation. The average age of the patients was 69.4, and all five patients reported improved low back pain compared with preoperative pain at 10- to 15-month follow-up. The authors concluded that cortical screw fixation was a good technique in patients requiring a reoperation because it obviates the need for previous hardware removal.

Our paper is the first prospective cohort study looking at cortical versus pedicle screw fixation in patients with lumbar degenerative disease and spinal instability, with or without an interbody fusion. None of the cases had prior instrumentation, as we sought to evaluate the pain outcomes in patients who underwent cortical screw fixation as the first-line technique.

Overall, there was no statistically significant difference in either average or peak immediate postoperative pain. However, there was a trend towards the cortical screw patients having less peak immediate postoperative pain (average pain score of 9 versus 7.94 in the pedicle group) (p $=0.09$ ). This is consistent with the hypothesis that a smaller incision with less muscle detachment and soft-tissue dissection in cortical screws may lead to less postoperative pain. This is also consistent with the findings in the Lee, et al. study where cortical screws were associated with lower immediate postoperative pain (within one week of surgery) compared to pedicle screws [12].

Although there was no difference in pain between cortical and pedicle screw patients at the six to 12-week follow-up, pedicle screw patients appeared to have less pain at the six to eightmonth follow-up (pain score of 6.14 in cortical patients versus 3.8 in pedicle patients) $(\mathrm{p}=$ 0.02). This is an interesting finding, as most of the biomechanical studies have shown superior pullout strength and stability in cortical screws compared to pedicle screws [6].

One explanation for these phenomena might be that, even though cortical screws are biomechanically stronger and prevent spinal micromotion and, therefore, pain generation in the short-term, long-term stability of the construct depends on the formation of a stable fusion mass. This might be happening more effectively in the pedicle screw cohort with posterolateral fusion in the lateral gutters, compared to the cortical screw cohort where arthrodesis was performed over the facet joints, but not in the lateral gutters. Although plain radiographs did not show any hardware failure in either group at the six to eight-month follow-up, long-term follow-up is needed to see if cortical screw patients have higher levels of pseudoarthrosis compared to pedicle screw patients and whether the difference in pain outcomes between the two cohorts remains divergent into the future. Notably, Lee, et al. did not find any difference in the pain scores or fusion rates between their two cohorts at one-year follow-up [12]. However, it has to be noted that they performed an interbody fusion (PLIF) in all of their patients, so their construct stability was boosted by the interbody fusion and was not solely reliant on the lateral gutter formation of a fusion mass in the long-term.

There are some limitations to our study, including the small sample size and the lack of randomization. Although patient characteristics overall were similar between the two groups, the pedicle screw group did have a higher percentage of female patients compared to the cortical group (Table 1). This may be the result of females having smaller diameter pedicles, thus, limiting the feasibility of the cortical trajectory technique. A 7-mm diameter was used as the minimum cut-off for performing cortical screw fixation in our study. Placing cortical trajectory lumbar screws in narrow pedicles is extremely challenging because of the medial to lateral course of the screw within the pedicle. The incidence of lateral vertebral breach with cortical screws seen in cadaveric specimens with narrow pedicles was found to be very high in the lab. This difference in the sex ratio between the two cohorts may confound the data, as 
women may have a different pain threshold compared to men due to mood, sex-role beliefs, or hormonal effects [16]. The study also only included patients from a single center with surgery performed by a single surgeon.

\section{Conclusions}

Our paper is the first prospective cohort study comparing pain outcomes for 33 patients who underwent cortical versus pedicle screw fixation in lumbar degenerative disease, with or without interbody fusion. Overall, cortical screw fixation results in similar to improved immediate postoperative pain but showed a trend towards worsening low back pain at the six to eight-month follow-up compared to pedicle screw patients. Both cohorts had statistically significant reduction in pain levels compared to preoperative pain after surgery (cortical at six to 12 weeks and pedicle at six to eight months). Our paper is a pilot study, and more prospective randomized clinical studies are needed to further evaluate postoperative pain, long-term functional outcomes, and fusion rates in patients who undergo cortical screw fixation.

\section{Additional Information Disclosures}

Human subjects: Consent was obtained by all participants in this study. Santa Clara Valley Medical Center (SCVMC) Institutional Review Board issued approval \#15-026ER. Animal subjects: All authors have confirmed that this study did not involve animal subjects or tissue. Conflicts of interest: In compliance with the ICMJE uniform disclosure form, all authors declare the following: Payment/services info: All authors have declared that no financial support was received from any organization for the submitted work. Financial relationships: All authors have declared that they have no financial relationships at present or within the previous three years with any organizations that might have an interest in the submitted work. Other relationships: All authors have declared that there are no other relationships or activities that could appear to have influenced the submitted work.

\section{Acknowledgements}

Yi-Ren Chen and Sayantan Deb contributed equally to this article. We thank Cheryl J. Christensen and Cindy H Samos for assistance with the manuscript and Paul Schiffmacher for the artwork in Figures 1 and 2.

\section{References}

1. Deyo RA, Gray DT, Kreuter W, Mirza S, Martin BI: United States trends in lumbar fusion surgery for degenerative conditions. Spine (Phila Pa 1976). 2005, 30:1441-45. 10.1097/01.brs.0000166503.37969.8a

2. Baluch DA, Patel AA, Lullo B, Havey RM, Voronov LI, Nguyen NL, Carandang G, Ghanayem AJ, Patwardhan AG: Effect of physiological loads on cortical and traditional pedicle screw fixation. Spine (Phila Pa 1976). 2014, 39:E1297-302. 10.1097/brs.0000000000000553

3. Calvert GC, Lawrence BD, Abtahi AM, Bachus KN, Brodke DS: Cortical screws used to rescue failed lumbar pedicle screw construct: a biomechanical analysis. J Neurosurg Spine. 2015, 22:166-72. 10.3171/2014.10.spine14371

4. Matsukawa K, Yato Y, Imabayashi H, Hosogane N, Asazuma T, Nemoto K: Biomechanical evaluation of the fixation strength of lumbar pedicle screws using cortical bone trajectory: a finite element study. J Neurosurg Spine. 2015, 23:471-78. 10.3171/2015.1.spine141103

5. Mobbs RJ: The "medio-latero-superior trajectory technique": an alternative cortical trajectory for pedicle fixation. Orthop Surg. 2013, 5:56-59. 10.1111/os.12027

6. Inceoğlu S, Montgomery WH Jr, St Clair S, McLain RF: Pedicle screw insertion angle and pullout strength: comparison of 2 proposed strategies. J Neurosurg Spine. 2011, 14:670-76. 
10.3171/2010.11.spine09886

7. Santoni BG, Hynes RA, McGilvray KC, Rodriguez-Canessa G, Lyons AS, Henson MA, Womack WJ, Puttlitz CM: Cortical bone trajectory for lumbar pedicle screws . Spine J. 2009, 9:366-373. 10.1016/j.spinee.2008.07.008

8. Wray S, Mimran R, Vadapalli S, Shetye SS, McGilvray KC, Puttlitz CM: Pedicle screw placement in the lumbar spine: effect of trajectory and screw design on acute biomechanical purchase. J Neurosurg Spine. 2015, 22:503-10. 10.3171/2014.10.spine14205

9. Ueno M, Sakai R, Tanaka K, Inoue G, Uchida K, Imura T, Saito W, Nakazawa T, Takahira N, Mabuchi K, Takaso M: Should we use cortical bone screws for cortical bone trajectory? . J Neurosurg Spine. 2015, 22:416-21. 10.3171/2014.9.spine1484

10. Matsukawa K, Yato Y, Kato T, Imabayashi H, Asazuma T, Nemoto K: In vivo analysis of insertional torque during pedicle screwing using cortical bone trajectory technique. Spine (Phila Pa 1976). 2014, 39:E240-45. 10.1097/brs.0000000000000116

11. Sansur CA, Caffes NM, Ibrahimi DM, Pratt NL, Lewis EM, Murgatroyd AA, Cunningham BW: Biomechanical fixation properties of cortical versus transpedicular screws in the osteoporotic lumbar spine: an in vitro human cadaveric model. J Neurosurg Spine. 2016, (Epub ahead of print):1-10. 10.3171/2016.2.SPINE151046

12. Lee GW, Son JH, Ahn MW, Kim HJ, Yeom JS: The comparison of pedicle screw and cortical screw in posterior lumbar interbody fusion: a prospective randomized noninferiority trial. Spine J. 2015, 15:1519-26. 10.1016/j.spinee.2015.02.038

13. Freeman MD, Woodham MA, Woodham AW: The role of the lumbar multifidus in chronic low back pain: a review. PM R. 2010, 2:142-46. 10.1016/j.pmrj.2009.11.006

14. Weinstein JN, Spratt KF, Spengler D, Brick C, Reid S: Spinal pedicle fixation: reliability and validity of roentgenogram-based assessment and surgical factors on successful screw placement. Spine (Phila Pa 1976). 1988, 13:1012-18.

15. Rodriguez A, Neal MT, Liu A, Somasundaram A, Hsu W, Branch CL Jr: Novel placement of cortical bone trajectory screws in previously instrumented pedicles for adjacent-segment lumbar disease using CT image-guided navigation. Technical note. Neurosurg Focus. 2014, 36:E9. 10.3171/2014.1.focus13521

16. Fillingim RB: Sex, gender, and pain: women and men really are different . Curr Rev Pain. 2000, 4:24-30. 10.1007/s11916-000-0006-6 